\title{
TECNOLOGIAS ASSISTIVAS E NECESSIDADES EDUCACIONAIS ESPECÍFICAS: DA OFERTA DE RECURSOS DE SOFTWARE AO PÚBLICO-ALVO
}

\author{
TECNOLOGÍAS ASISTIVAS Y NECESIDADES EDUCATIVAS ESPECÍFICAS: DESDE \\ OFRECER RECURSOS DE SOFTWARE AL PÚBLICO OBJETIVO
}

\author{
ASSISTIVE TECHNOLOGIES AND SPECIFIC EDUCATIONAL NEEDS: THE \\ OFFERING OF SOFTWARE RESOURCES TO THE TARGET AUDIENCE
}

\author{
Tatiele Bolson MORO ${ }^{1}$ \\ Ygor CORRÊA ${ }^{2}$ \\ Carla Beatris VALENTINI ${ }^{3}$ \\ Valdinei MARCOLLA ${ }^{4}$ \\ Eduardo CARDOSO 5
}

RESUMO: Este estudo investiga quais são os principais tipos de Tecnologias Assistivas (TAs) e Necessidades Educacionais Específicas (NEEs) no contexto educacional. A literatura adotada apoia-se na área da Educação Inclusiva e legislações oficiais. Nesta pesquisa qualitativa e documental foram analisadas 42 fichas cadastrais de alunos para a identificação das NEEs, seguida do levantamento das TAs por meio de visita guiada. O estudo aborda as TAs como recursos de Auxílio e principalmente as do tipo software. O resultado da análise de dados apontou para 16 NEEs. Quanto às TAs, identificou-se 41 tipos, sendo 16 TAs Auxílio e 25 TAs software. Para, além disso, constatou-se que há uma maior oferta de TAs destinada aos alunos com deficiência visual e não para alunos com TDAH, NEE que predomina na Instituição.

PALAVRAS-CHAVE: Tecnologias assistivas. Necessidades educacionais específicas. Educação inclusiva. Recursos de software.

RESUMEN: Este estudio investiga los principales tipos de Tecnologías Asistivas (TA) y necesidades educativas especificas (NEE) en el contexto educativo. La literatura adoptada se apoya en la área de Educación Inclusiva y la legislación oficial. En esta investigación cualitativa y documental, se analiza 42 registros de estudiantes para identificación de NEE, seguida de la encuesta de TA a través de una visita guiada. El estudio aborda las TA como

\footnotetext{
${ }^{1}$ Universidade de Caxias do Sul (UCS), Caxias do Sul - RS - Brasil. Doutoranda no Programa de Pós-Graduação em Educação. ORCID: http://orcid.org/0000-0002-3302-8953. E-mail: tati.bm@gmail.com

${ }^{2}$ Universidade de Caxias do Sul (UCS), Caxias do Sul - RS - Brasil. Pós-Doutorando no Programa de PósGraduação em Educação. ORCID: https://orcid.org/0000-0002-3526-9195. E-mail: correaygorprof@gmail.com

${ }^{3}$ Universidade de Caxias do Sul (UCS), Caxias do Sul - RS, Brasil. Professora e Coordenadora do Programa de Pós-Graduação em Educação. Doutorado em Informática na Educação (UFRGS). ORCID: https://orcid.org/00000003-0355-7712. E-mail: cbvalent@ucs.br

${ }^{4}$ Instituto Federal de Educação, Ciência e Tecnologia Catarinense (IFC), Videira - SC - Brasil. Professor do Ensino Básico, Técnico e Tecnológico no Curso de Pedagogia. Doutorado em Educação (UFPEL). ORCID: http://orcid.org/0000-0002-9057-93992. E-mail: valdinei.marcolla@gmail.com

${ }^{5}$ Universidade Federal do Rio Grande do Sul (UFRGS), Porto Alegre - RS - Brasil. Professor Adjunto no Departamento de Design e Expressão Gráfica e Professor Colaborador no Programa de Pós-Graduação em Design. Doutorado em Design (UFRGS). ORCID: https://orcid.org/0000-0002-1202-1779. E-mail: eduardo.cardoso@ufrgs.br
} 
recursos de ayuda y principalmente los del tipo de software. El resultado del análisis de datos apuntó a 16 NEEs. Quanto a las TA, se identificaron 41 tipos, 16 TA de ayuda y 25 TA de software. Además, se encontró que hay una mayor oferta de asistencia técnica para estudiantes con discapacidad visual y no para estudiantes con TDAH, NEE que predomina en la Institución.

PALABRAS CLAVE: Tecnologías asistivas. Necesidades educativas específicas. Educación inclusiva. Recursos de software.

ABSTRACT: This study investigates which are the main types of Assistive Technologies (ATs) and Specific Educational Needs (SENs) in the educational context. The literature adopted is supported in the area of Inclusive Education and official legislation. In this qualitative research, 42 student records were analyzed to identify the SENs, followed by the cataloging of the ATs through visits to the institution. The study addresses ATs such as help and software resources, especially those of the software type. The result of the data analysis pointed to 41 ATs, being 16 hardware ATs and 25 software ATs, divided into ten different categories. In addition, it was found that there is a greater offer of ATs for students with visual disabilities and not for students with ADHD, SENs that predominates in the institution.

KEYWORDS: Assistive technologies. Specific educational needs. Inclusive education. Software resources.

\section{Introdução}

Este artigo tem origem em estudo desenvolvido no Instituto Federal de Ciência, Educação e Tecnologia do Rio Grande do Sul (IFRS), Campus Caxias do Sul e procurar-se-á analisar dados referentes às Necessidades Educacionais Específicas (NEEs) e os tipos de Tecnologias Assistivas (TAs) presentes no cotidiano educacional. Aliado a isso, pretende-se identificar se há uma oferta coerente de TAs (CAT, 2009) em relação ao(s) tipo(s) de NEEs. Neste horizonte, infere-se que a condução desta pesquisa se justifica, na medida em que se possa, a partir da análise de dados, apontar para a gestão institucional questões que envolvem a organização desses recursos com o intuito de discutir a necessidade de aquisição, renovação ou substituição de TAs.

O referencial teórico adotado abarca a literatura sobre Deficiência e Necessidades Especiais (NE) (DINIZ; BARBOSA; SANTOS, 2009; BRASIL, 2014) para conceituar a temática proposta, assim como se apoia nas legislações vigentes, em relação à Educação Inclusiva (BRASIL, 2004; 2008; 2011; 2015b; 2016). Para tanto, apresenta-se o conceito de Deficiência, a partir das perspectivas do modelo médico e social, (DINIZ; BARBOSA; SANTOS, 2009; BISOL; PEGORINI; VALENTINI, 2017), sob a premissa de uma educação contemporânea que deve, em outras palavras, instigar e desencadear processos educacionais 
que fomentem a autonomia e o desenvolvimento integral dos alunos com NEEs, visando à inserção desses em uma sociedade mais equânime do ponto de vista sociocultural (BERSCH, 2017).

Em seguida, relativo às TAs, apresenta-se duas categorias: Auxílio e de Acessibilidade ao Computador do tipo Software, (SONZA et al., 2015b; BERSCH, 2017), na tentativa de verificar se esses dois tipos de TAs são ofertadas no IFRS-Caxias do Sul. Em linhas gerais, discorre-se sobre a abordagem educacional inclusiva do IFRS, enquanto Instituição de ensino e, posteriormente, caracteriza-se o IFRS-Caxias do Sul, enquanto lócus de coleta de dados. A definição desta Instituição como campo de investigação se dá pela mesma ter implantado a Lei $\mathrm{n}^{\circ}$ 13.409 (BRASIL, 2016), que dispõe sobre a "reserva de vagas para pessoas com deficiência nos cursos técnicos de nível médio e superior das instituições federais de ensino" e também por ser contexto de pesquisa tese de doutoramento de um dos autores.

Esta é uma pesquisa qualitativa e exploratória (SAMPIERI; COLLADO; LUCIO, 2013), que se utiliza da análise documental (CELLARD, 2008) para desenvolver uma sistematização acerca das NEEs e TAs disponíveis pela Instituição. A partir disso, dividiu-se a análise em duas etapas: (i) na primeira, o mapeamento dos tipos de NEEs (Deficiências e NEs) - tendo por base dados oriundos de 42 fichas cadastrais de alunos com NEE, durante o período de 2015 a 2019, os quais foram classificados em categorias, a partir da legislação brasileira vigente (BRASIL, 2004; 2008; 2011); já (ii) na segunda etapa foram levantados os tipos de TAs ofertadas na Instituição, essas foram catalogadas a partir de visita guiada; o viés investigativo teve como enfoque o detalhamento das TAs de acessibilidade ao computador do tipo software. A seguir, discorre-se acerca dos conceitos de Deficiência e Educação Inclusiva.

\section{Educação inclusiva: da deficiência às necessidades específicas ao conceito de necessidades educacionais específicas}

Para definir o que se entende por deficiência é necessário considerar as especificações de diversos documentos (BRASIL, 2004; 2008; 2011; 2015b; 2016), organizações e investigações, que estudam sobre o assunto. Os estudos atuais apontam para pelo menos duas perspectivas de concepções acerca da deficiência: o modelo médico e o modelo social (BISOL; PEGORINI; VALENTINI, 2017). O modelo médico toma a deficiência como problema individual, que causa desvantagens e limitações, buscando soluções para que o corpo "doente" se aproxime da condição considerada normal (DINIZ; BARBOSA; SANTOS, 2009). Já o modelo social: 
[...] parte da ideia de que as diferenças corporais, sensórias e intelectuais não constituem anomalias ou doenças, mas diferentes formas de funcionamento, de tal modo que não se pode predizer a existência de uma norma a todos os seres humanos (BISOL; PEGORINI; VALENTINI, 2017, p. 94).

Essa segunda perspectiva aponta para as barreiras atitudinais construídas pela sociedade, o que tem desencadeado aporte para políticas, a legitimação de direitos, acessibilidade, e a desconstrução do preconceito e discriminação social. No entanto, a concepção de deficiência neste estudo está ancorada a partir do modelo médico, tendo em vista que as políticas governamentais voltadas a pessoa com deficiência estão pautadas na concepção da doença como fator limitante.

No contexto brasileiro existem várias leis e decretos (BRASIL, 2004; 2008; 2011; 2015b; 2016) que estabelecem um caminho sobre a inclusão social e escolar, a acessibilidade e a Educação Inclusiva, não só da pessoa com deficiência(s), mas das pessoas que possuem Necessidades Especiais (NEs). Na área da Educação, em se tratando de abordagens educacionais, deficiências e NEs são, geralmente, unificadas na nomenclatura Necessidades Educacionais Específicas (NEEs), muito embora as especificidades de cada uma devam ser consideradas. A referida nomenclatura também é adotada pela Instituição, na qual esta pesquisa foi realizada, o que levou os autores deste estudo à adoção do conceito de NEE, com base na literatura da área (SONZA et al., 2015).

Em 2014 foi estabelecido o Plano Nacional de Educação (PNE) que abordou na Meta 04 sobre a Educação Especial (BRASIL, 2015a; 2016), para que ela se destinasse às pessoas com deficiência (BRASIL, 2004), sejam elas originadas por deficiência física, auditiva (baixa audição e surdez), visual (baixa visão ou cegueira) ou intelectual, bem como NEs (BRASIL, 2008; 2011) como Altas Habilidades, Superdotação, dentre outras. O PNE traz em seu texto o objetivo de construir uma Educação que atendesse a todos, com acesso e qualidade ao ensino público (BRASIL, 2008b; 2015a), sobre a premissa de uma Educação Inclusiva. A partir disso, surgem outras leis e decretos que dão aporte legal para a Educação Inclusiva no contexto nacional, tais como: Decretos $n^{\circ} 5.296$ (BRASIL, 2004), Decreto $n^{\circ} 6.571$ (BRASIL, 2008) e Decreto $n^{\circ} .7 .611$ (BRASIL, 2011), Lei n 13.146 (BRASIL, 2015b), Lei n 13.409 (BRASIL, 2016) com o intuito de promover a equidade, a uniformidade (através da categorização das deficiências e das NEs), os direitos e a justiça, entendendo que todos são iguais perante a Lei.

No horizonte inclusivo, Beyer (2015) postula que o conceito de Educação Inclusiva é caracterizado como um novo princípio educacional, que defende a heterogeneidade na classe escolar, como situação provocadora de interações entre crianças com NEs. Carvalho (2016), 
por sua vez, cita que se deve educar, conforme as diferenças e as necessidades individuais, sem que outras condições, sejam elas econômicas ou até de geográficas, acarretem em impedimentos à aprendizagem. Assim, ainda conforme a autora, a Educação Inclusiva é compreendida como educação de boa qualidade para todos, buscando meios de remover barreiras para a aprendizagem e para a participação dos alunos. Uma forma de remover barreiras é fazer o uso de tecnologias assistivas, desta forma na próxima seção é apresentada uma breve contextualização sobre o tema.

\section{Tecnologia assistiva}

Essa seção dedica-se às tecnologias (GARCIA et al., 2012) que, de modo geral, proporcionam transformações na vida das pessoas, principalmente, na execução de tarefas, que, segundo Sonza et al. (2015), permitem tornar a vida mais prática. Em se tratando de pessoas com deficiência ou com NEs, isso não é diferente, posto que as tecnologias, em especial, as digitais (GARCIA et al., 2012), também permitem auxiliar as pessoas quanto às suas demandas. Em relação ao contexto educacional, a tecnologia pode ajudar nos processos de desenvolvimento humano, de forma que haja uma movimentação dos saberes do sujeito de uma zona de desenvolvimento ${ }^{6}$ para outra, esse movimento compreende o desenvolvimento das capacidades cognitivas, por meio das relações com o outro, permitindo a aprendizagem de um novo conhecimento ou o aperfeiçoamento de um processo existente (VIGOTSKI, 1991).

A Tecnologia Assistiva (TA) envolve uma gama de recursos que contribuem para proporcionar ou ampliar as habilidades funcionais das pessoas com NEE (SONZA et al., 2015; 2015; RODRIGUES, 2017). O conceito de TA é proposto pelo Comitê de Ajudas Técnicas (CAT, 2009), o qual apresenta uma clara definição para essa área de delineamento interdisciplinar que prevê “" [...] produtos, recursos, metodologias, estratégias, práticas e serviços que objetivam promover a funcionalidade, relacionada à atividade e participação, de pessoas com deficiência, incapacidades ou mobilidade reduzida" (CAT, 2009, p. 14).

O referido comitê ainda afirma que a utilização de TAs têm por finalidade promover “autonomia, independência, qualidade de vida e inclusão social” (CAT, 2009, p. 14) de seus usuários em uma sociedade mais equânime. Também se pode dizer que a TA ajuda a identificar todos os recursos e serviços que contribuem para ampliar as habilidades funcionais das pessoas com NEE, promovendo a inclusão e diminuindo os problemas encontrados pelos indivíduos

${ }^{6}$ Para aprofundamento os conceitos de Zona de Desenvolvimento, Real e Proximal, ver conceitos de Vigotski (1991). 
(BERSCH, 2017). O propósito da TA consiste em "ampliar a comunicação, a mobilidade, o controle do ambiente, as possibilidades de aprendizado, de trabalho e de integração na vida familiar, com amigos e na sociedade em geral" (SONZA, 2013, p. 200).

As TAs podem ser classificadas em serviços e recursos (ORLANDO FILHO, 2006). Os serviços auxiliam a pessoa com NEE na seleção, aquisição ou uso de TA ou até mesmo de, por exemplo, a interpretação realizada por intérpretes de libras. Já os recursos são equipamentos, componentes, produtos ou sistemas que são usados para aumentar ou melhorar as capacidades funcionais das pessoas com NEE. Os recursos são subdivididos em: (a) Auxílios para a vida diária e prática; (b) Comunicação Aumentativa e Alternativa (CAA); (c) Recursos de Acessibilidade ao computador; (d) Sistemas de Controle de Ambiente; (e) Projetos Arquitetônicos para Acessibilidade; (f) Órteses e Próteses; (g) Adequação Postural; (h) Auxílios de Mobilidade; (i) Auxílios para Cegos ou com Visão Subnormal; (j) Auxílios para pessoas com surdez ou com déficit auditivo; (l) Adaptações em veículos; e (m) Esportes e lazer (SONZA et al., 2015; BERSCH, 2017).

Os recursos não classificados como acessibilidade ao computador (softwares) são nomeados, neste estudo, como recursos de Auxílio, pois se configuram como TAs que se voltam a promoção da acessibilidade e a facilitação das ações diárias, como, por exemplo, a lupa, o engrossador de lápis, a prancha braile ou o rotulador braile, sobre outras finalidades de ajuda às pessoas com deficiência ou NE.

Os softwares são recursos idealizados para tornar o uso do computador acessível para pessoas que possuem algum tipo de privação, seja ela sensorial (auditiva ou visual), intelectual ou motora. Os dispositivos podem ser de entrada, teclados e mouses virtuais, e de saída, leitores de tela, ajustes de cores, lupas, entre outros. Percebe-se a importância da disponibilização de softwares que ajudem o aluno e o professor no processo de ensino aprendizagem (ORLANDO FILHO, 2006), como é o caso, por exemplo, do uso de softwares gratuitos. Esses softwares podem ser copiados e distribuídos gratuitamente, sem a possibilidade de modificação do código fonte (MAIA, 2011). Ressalta-se que eles, podem ser instalados nos computadores das instituições de ensino público, representando assim o acesso e a variedade de ferramentas no processo de aprendizagem das pessoas com NEEs. Na próxima seção, apresenta-se, a metodologia de pesquisa deste estudo. 


\section{Metodologia}

Esta é uma pesquisa qualitativa e exploratória (SAMPIERI; COLLADO; LUCIO, 2013) que buscou por meio da análise documental (CELLARD, 2008) sistematizar um levantamento das especificidades atendidas e dos recursos disponíveis. Para tanto, procurou-se organizar e dividir a análise em duas etapas, a saber: mapeamento dos tipos de NEEs e catalogação das TAs ofertadas na Instituição.

A primeira envolveu o mapeamento dos tipos de Necessidades Educacionais Específicas (NEEs), que abarcam deficiências e NEs, presentes no IFRS-Caxias do Sul. Essa etapa pautase na análise de 42 fichas cadastrais de alunos, as quais foram anonimizadas pela Instituição originária. As NEEs foram classificadas em categorias, a partir da legislação brasileira vigente (BRASIL, 2004; 2008; 2011) como será visto na seção de análise de dados. O mapeamento das NEEs abrangeu o período de 2015 a 2019 e refere-se ao ensino médio técnico (integrado e subsequente) e ao ensino superior;

A segunda consistiu na catalogação das TAs ofertadas na Instituição, refere-se apenas ao ano de 2019 e concretizou-se por meio de visita guiada ao IFRS-Caxias do Sul, como exploração in loco, as quais contaram com o acompanhamento de uma Técnica em Atendimento Educacional Especializado (AEE). Para a catalogação das TAs utilizou um tablet e, a posteriori, fez-se uso de uma planilha Microsoft Excel, para fins de registro, de categorização e de armazenamento dos dados analisados. As TAs foram catalogadas e classificadas enquanto recursos de Auxílio e TAs de Software, de acordo com a literatura baseada em Sonza et al. (2015) e Bersch (2017).

Uma vez que o foco da pesquisa está direcionado para a relação das TAs de software e com o público-alvo, optou-se por apresentá-las classificadas em categorias temáticas por funcionalidade, a saber: (a) Leitores de Telas; (b) Ampliadores de telas; (c) Mudança de Cores; (d) Comunicação Aumentativa Alternativa (CAA); (e) Alternativas de Mouse Virtual e (f) Alternativas de Teclado Virtual.

Para tanto, no texto apresenta-se o nome da TA e seu endereço eletrônico, para que o leitor possa localizá-las na Internet, assim como a associação dessa com o tipo de NEE para qual foi destinada no IFRS-Caxias do Sul. Não obstante, compreendeu-se como relevante, na tentativa de analisar a oferta de TAs de software versus público-alvo, investigar a frequência de uso das TAs em questão, durante o ano de 2019, a partir da legenda de uso (i) diário, (ii) semanal; (iii) quinzenal; (iv) mensal ou (v) sem utilização. Todos os dados que compuseram o corpus de pesquisa foram obtidos junto ao Núcleo de Atendimento às Pessoas com 
Necessidades Educacionais Específicas (NAPNE). Na próxima seção, são apresentados os achados desta pesquisa.

\section{Análise de dados}

Relativo à análise de dados, na primeira etapa foram analisadas 42 fichas cadastrais de alunos com diferentes NEEs, do período de 2015 a 2019, o que permitiu a extração de dados, que ao serem analisados e tabulados evidenciaram a ocorrência de 16 tipos de NEEs. Estas foram divididas entre alunos com deficiência e alunos com NEs. Assim, na primeira modalidade subdividiu-se em 4 categorias: Deficiência Física; Deficiência Auditiva; Deficiência Visual; Deficiência Intelectual a qual, com base no Decreto $n^{0} 5.296$ (BRASIL, 2004), é composta por 11 tipos de deficiências identificas na Instituição. A segunda modalidade é formada por 1 categoria denominada por 'Outras NEs', que é composta por 5 tipos de NEs, respeitando os Decreto $n^{0} 6.571$ (BRASIL, 2008) e Decreto $n^{\circ} .7 .611$ (BRASIL, 2011), por serem essas apresentadas de modo dissociado à definição de deficiência (vide quadro 1).

\section{Quadro 1 - Categorização das NEEs}

\begin{tabular}{|c|l|c|}
\hline CATEGORIA & \multicolumn{1}{|c|}{ TIPO } & $\begin{array}{c}\text { PERCENTUAL } \\
\text { DE ALUNOS }\end{array}$ \\
\hline $\begin{array}{c}\text { Deficiência } \\
\text { Física }\end{array}$ & $\begin{array}{l}\text { Paralisia cerebral (4 alunos); } \\
\text { Deficiência física nos membros superiores (3); } \\
\text { Hemimelia Fibular (1), Neuropatia de Charcot Marie Tooth (1); } \\
\text { Paralisia da Prega Vocal (1); } \\
\text { Redução do Equilíbrio Corpóreo (1); }\end{array}$ & $26,4 \%$ \\
\hline $\begin{array}{c}\text { Deficiência } \\
\text { Auditiva }\end{array}$ & $\begin{array}{l}\text { Surdez (4); } \\
\text { Baixa audição (3); }\end{array}$ & \multirow{2}{|c|}{$16,6 \%$} \\
\hline $\begin{array}{c}\text { Deficiência } \\
\text { Visual }\end{array}$ & Baixa visão (4); & $9,5 \%$ \\
\hline $\begin{array}{c}\text { Deficiência } \\
\text { Intelectual }\end{array}$ & $\begin{array}{l}\text { Déficit Neurológico (3); } \\
\text { Síndrome de Down (1); }\end{array}$ & $9,5 \%$ \\
\hline $\begin{array}{l}\text { Síndrome de Tourette (1); } \\
\text { Transtorno Global de Desenvolvimento (TGD) (1); } \\
\text { Altas Habilidades/Superdotação (AS/SD) (1); } \\
\text { Transtorno do Espectro Autista (3); } \\
\text { Transtorno do Déficit de Atenção e Hiperatividade (TDAH) (9). }\end{array}$ & \\
\hline
\end{tabular}

Fonte: Elaborado pelos autores

Na segunda etapa foram catalogadas as TAs ofertadas pelo IFRS-Caxias do Sul, apenas no ano de 2019, como forma de exploração in loco. Para esse levantamento foi realizada visita guiada às dependências da Instituição, para fins de concretizar o levantamento. Diante disso, foram elencadas 41 TAs, as quais foram divididas a partir de CAT (2009), Sonza et al. (2015) e Bersch (2017) em 16 TAs do tipo Auxiliar e 25 TAs de Software, estes foram subdivididos em 10 subcategorias como apresentado no Quadro 2.

RPGE- Revista on line de Política e Gestão Educacional, Araraquara, v. 24, n. 3, p. 1242-1256, set./dez. 2020. e-ISSN:1519-9029. 
Quadro 2 - Levantamento das TAs de Software e de Auxílio

\begin{tabular}{|c|c|c|c|}
\hline TA - SOFTWARE & TOTAL & TA - AUXÍLIO & TOTAL \\
\hline Leitores de Tela & 5 & Recursos de Leitura & 4 \\
\hline Ampliadores de Tela & 6 & Recursos de Escrita & 4 \\
\hline Mudança de Cores & 4 & Mobilidade & 2 \\
\hline Comunicação Aumentativa e Alternativa & 4 & Materiais Didáticos & 6 \\
\hline Alternativas de Mouse Virtual & 4 & & \\
\hline Alternativa de Teclado Virtual & 2 & & \\
\hline
\end{tabular}

Fonte: Elaborado pelos autores

A oferta de TAs de Software e de Auxílio foi compreendida em consonância com o Art. $3^{\circ}$, Lei $n^{\circ} 13.146$ (BRASIL, 2015), que prevê o uso de TAs, em como recursos pedagógicos, no ensino de Educação Básica ou Superior, tendo em vista que as TAs têm sido disponibilizadas em número expressivo e, relativamente, de acordo com o público-alvo da Instituição. Entendese que a utilização de uma TA pode possibilitar a autonomia e a independência do discente, bem como seu usada para fins de aprendizagem ou consolidação de um conhecimento preexistente do aluno (BRASIL, 2015; VIGOTSKI, 1991).

Assim foram identificados os recursos de Auxílio que compreendem: Recursos de Leitura (Lupa, Leitor de Arquivos Digitais, Teclado para Deficientes Visuais (colmeia), Leitor Autônomo com Digitalizador de Voz Integrado); Recursos de Escrita (Engrossador de Lápis, Reglete; Prancha e Punção, Rotulador Braile); Mobilidade (Muletas, Bengalas); Materiais Didáticos (Multiplano, Geoplano, Soroban, Notebook, Xadrez para Deficientes Visuais; Alfabeto Braile).

O foco da pesquisa foi direcionado para a relação das TAs de Software e sua relação com o público-alvo, assim foram classificadas em categorias conforme a sua funcionalidade: (a) Leitores de Telas; (b) Ampliadores de telas; (c) Mudança de Cores; (d) Comunicação Aumentativa Alternativa (CAA); (e) Alternativas de Mouse Virtual e (f) Alternativas de Teclado Virtual. No Quadro 3 foram listadas as TAs de software, as NEE e a frequência de solicitação dos elementos, conforme anunciado na metodologia, tabulou-se o nome da TA, seu endereço eletrônico, para que o leitor deste artigo possa localizá-las na Internet e sua associação com o tipo de NEE para qual essa foi destinada no IFRS-Caxias do Sul. Ainda, foi elencado a frequência de uso das TAs de Software a partir de uma legenda de uso (i) diário, (ii) semanal; (iii) quinzenal; (iv) mensal ou (v) sem utilização durante o ano de 2019. 
Quadro 3 - Catalogação das TAs de Software

\begin{tabular}{|c|c|c|c|}
\hline RECURSOS & $\begin{array}{l}\text { ENDEREÇO } \\
\text { ELETRÔNICO }\end{array}$ & NEE & $\begin{array}{l}\text { FREQUÊNCIA DE } \\
\text { SOLICITAÇÃO }\end{array}$ \\
\hline \multicolumn{4}{|l|}{ LEITORES DE TELA } \\
\hline $\begin{array}{l}\text { NonVisual desktop } \\
\text { Access (NVDA) }\end{array}$ & https://rb.gy/mntei7 & Baixa visão & Mensal \\
\hline Orca & https://rb.gy/oxavwq & Baixa visão & Sem utilização \\
\hline VoiceOver & Dispositivo Mac & Baixa visão & Sem utilização \\
\hline TalkBack & Dispositivo Microsoft & Baixa visão & Sem utilização \\
\hline DosVox & https://rb.gy/sigaoq & Baixa visão & Quinzenal \\
\hline \multicolumn{4}{|c|}{ AMPLIADORES DE TELA } \\
\hline Lupa do Windows & Dispositivo Microsoft & $\begin{array}{l}\text { Baixa Visão, Paralisia } \\
\text { Cerebral }\end{array}$ & Semanal \\
\hline LentePro & https://rb.gy/t2wcds & $\begin{array}{l}\text { Baixa Visão, Paralisia } \\
\text { Cerebral }\end{array}$ & Sem utilização \\
\hline $\begin{array}{l}\text { Virtual Magnifying } \\
\text { Glass }\end{array}$ & https://rb.gy/zbb0fu & $\begin{array}{l}\text { Baixa Visão, Paralisia } \\
\text { Cerebral }\end{array}$ & Sem utilização \\
\hline Lightning 3 & $\begin{array}{l}\text { Página oficial } \\
\text { desativada }\end{array}$ & $\begin{array}{l}\text { Baixa Visão, Paralisia } \\
\text { Cerebral }\end{array}$ & Sem utilização \\
\hline Magnifixer & https://rb.gy/schlmu & $\begin{array}{l}\text { Baixa Visão, Paralisia } \\
\text { Cerebral }\end{array}$ & Sem utilização \\
\hline Zoomlt & https://rb.gy/j1woum & $\begin{array}{l}\text { Baixa Visão, Paralisia } \\
\text { Cerebral }\end{array}$ & Sem utilização \\
\hline \multicolumn{4}{|l|}{ MUDANÇA DE CORES } \\
\hline High Contrast & https://rb.gy/hzlbt3 & Baixa Visão & Sem utilização \\
\hline Dark Reader & https://rb.gy/zepme7 & Baixa Visão & Sem utilização \\
\hline $\begin{array}{l}\text { Dark Background and } \\
\text { Light Text }\end{array}$ & https://rb.gy/ibscgs & Baixa Visão & Sem utilização \\
\hline $\begin{array}{l}\text { Blank Your Monitor + } \\
\text { Easy Reading }\end{array}$ & https://rb.gy/5guh2r & Baixa Visão & Sem utilização \\
\hline \multicolumn{4}{|c|}{ COMUNICAÇÃO AUMENTATIVA E ALTERNATIVA (CAA) } \\
\hline AraBoard & https://rb.gy/gpccir & $\begin{array}{l}\text { Paralisia Cerebral, Baixa } \\
\text { Audição, Paralisia da Prega } \\
\text { Vocal }\end{array}$ & Sem utilização \\
\hline Prancha Fácil & https://rb.gy/0k8mg5 & $\begin{array}{l}\text { Paralisia Cerebral, Baixa } \\
\text { Audição, Paralisia da Prega } \\
\text { Vocal }\end{array}$ & Mensal \\
\hline Plaphoons & https://rb.gy/zsqqwf & $\begin{array}{l}\text { Paralisia Cerebral, Baixa } \\
\text { Audição, Paralisia da Prega } \\
\text { Vocal }\end{array}$ & Sem utilização \\
\hline Scala & https://rb.gy/p66bc9 & $\begin{array}{l}\text { Paralisia Cerebral, Baixa } \\
\text { Audição, Paralisia da Prega } \\
\text { Vocal, TDAH }\end{array}$ & Mensal \\
\hline \multicolumn{4}{|c|}{ ALTERNATIVAS DE MOUSE VIRTUAL } \\
\hline Câmera Mousem & https://rb.gy/t0xsab & $\begin{array}{l}\text { Paralisia Cerebral, } \\
\text { Deficiência Física Membros } \\
\text { Superiores }\end{array}$ & Sem utilização \\
\hline eViacam & $\begin{array}{l}\text { https://eviacam.crea- } \\
\text { si.com/ }\end{array}$ & $\begin{array}{l}\text { Paralisia Cerebral, } \\
\text { Deficiência Física Membros } \\
\text { Superiores }\end{array}$ & Sem utilização \\
\hline HeadDev & https://rb.gy/zxlut8 & $\begin{array}{l}\text { Paralisia Cerebral, } \\
\text { Deficiência Física Membros } \\
\text { Superiores }\end{array}$ & Sem utilização \\
\hline Headmouse & https://rb.gy/mkvdkj & $\begin{array}{l}\text { Paralisia Cerebral } \\
\text { Deficiência Física membros } \\
\text { superiores. }\end{array}$ & Sem utilização \\
\hline
\end{tabular}

RPGE- Revista on line de Política e Gestão Educacional, Araraquara, v. 24, n. 3, p. 1242-1256, set./dez. 2020. e-ISSN:1519-9029. 


\begin{tabular}{|l|l|l|l|}
\hline $\begin{array}{l}\text { Teclado Virtual do } \\
\text { Windows }\end{array}$ & https://rb.gy/fllo2k & $\begin{array}{l}\text { Paralisia Cerebral, } \\
\text { Deficiência Física Membros } \\
\text { Superiores, Baixa Visão }\end{array}$ & Diário \\
\hline MouseKey & https://rb.gy/rppu04 & $\begin{array}{l}\text { Paralisia Cerebral, } \\
\text { Deficiência Física Membros } \\
\text { Superiores, Baixa visão }\end{array}$ & Diário \\
\hline
\end{tabular}

Fonte: Elaborado pelos autores

Com base no detalhamento apresentado Quadro 03, relativa às TAs de Software, foi possível constatar que existe uma maior oferta de TAs destinada aos alunos com deficiência visual, o que não é condizente com o número de alunos com TDAH, NEE que predomina na Instituição. Em relação à categoria de Leitores de Tela, constatou que apenas dois softwares (NonVisual desktop Access (NVDA); DosVox) têm sido utilizados, o que representa 4,9\% da totalidade de recursos disponibilizados pelo IFRS-Caxias do Sul.

No tocante à categoria Ampliadores de Tela, verificou-se apenas a Lupa do Windows é utilizada, representando $2,4 \%$ da totalidade das TAs. O recurso Comunicação Aumentativa e Alternativa (CAA) apresentou dois softwares, os quais são usados (Prancha Fácil e Scala), representando $4,9 \%$ do total de recursos. Relativo ao recurso Alternativas de Teclado Virtual, observou-se que são usados os dois instrumentos que são disponibilizados pela Instituição (Teclado Virtual do Windows e Mouse Key), mostrando 4,9\% do total das TAs. Já quanto aos recursos Mudança de Cores e Alternativas para Mouse Virtual, não se observou uso para essas ferramentas.

A partir desse levantamento, da visita à Instituição e das informações apontadas pelo NAPNE, também se pode inferir sobre a frequência de solicitação dos recursos de software. Desta forma, depreendeu-se que dentre os 25 recursos de software disponibilizados pela Instituição, a frequência de uso foi: $72 \%$ sem utilização; 12\% mensalmente; 4\% quinzenalmente; $4 \%$ semanalmente e $8 \%$ diariamente. Como verificado, predomina a não utilização da maior parte de TAs de Software, aspecto que aponta para a não adesão das TAs, talvez por falta de conhecimento dos professores, em relação à utilização desses recursos computacionais relacionados ao ensino e aprendizagem.

Desta forma, pode-se constatar que os softwares ofertados pelo IFRS-Caxias do Sul são, em sua maioria, voltados para alunos que possuem deficiência Visual (4 alunos) e Paralisia Cerebral (4 alunos), estes representam 19\% do total dos alunos com NEEs. Acredita-se que os alunos com deficiência auditiva não fizeram uso das TAs por terem acesso à Intérpretes de Libras. Os demais alunos com NEEs não foram contemplados com recursos de TAs de Software, por não haver procura ou por não haver necessidade de auxílio de softwares. 
O IFRS-Caxias do Sul dispõe de softwares gratuitos, os quais são de fácil acesso para a Instituição poder instalar e disponibilizar aos alunos e professores. Esse tipo de software tem a possibilidade de ser instalado, por exemplo, por um familiar, no(s) equipamento(s) usado(s) em âmbito doméstico pelos alunos com NEEs, o que permite que os alunos se tornem ainda mais familiarizados com o uso de determinado recurso computacional para fins de aprendizagem. Assim o aluno pode usar as mesmas TAs em sua casa, o que pode facilitar seu desenvolvimento escolar.

\section{Considerações finais}

Este artigo mapeou, a partir dos Decretos $\mathrm{n}^{\circ} 5.296$ (BRASIL, 2004), $\mathrm{n}^{\circ} 6.571$ (BRASIL, 2008) e n $n^{\circ} .7 .611$ (BRASIL, 2011), as NEEs dos alunos do IFRS-Caxias do Sul, bem como os recursos de TAs de Auxílio, em especial, de Software. Depreendeu-se que o maior número de alunos com NEEs são os que apresentam TDAH, seguidos de surdez, baixa visão e paralisia cerebral. No que tange à catalogação das TAs, foi possível elencar os recursos de Auxílio e de software existentes na Instituição, o que permitiu identificar um maior número de TAs voltadas à acessibilidade computacional do tipo software.

Assim, o estudo procurou focar nesse tipo de recurso, o qual foi categorizado, conforme o seu tipo e sua relação com o público alvo. Ao longo desse processo, inferiu-se que a Instituição tem disponibilizado ferramentas gratuitas para os alunos e professores. A gestão institucional tem adotado como princípio a promoção do uso de ferramentas gratuitas, entendendo o significado político e social da defesa do desenvolvimento softwares gratuitos e o papel que estes podem ter na efetivação da inclusão escolar de alunos carentes e com NEEs. Apesar disso, ficou evidente a necessidade de ações voltadas à formação de professores e técnicos educacionais com o intuito de discutir e apresentar formas de uso das TAs.

Além disso, percebeu-se a necessidade de uma intervenção coordenada pela equipe gestora no intuito de garantir a disponibilização de TAs, que atendam as distintas NEEs. Haja vista, que se identificou uma maior oferta de TAs para alunos que possuem deficiência visual ou paralisia cerebral e não os alunos com TDAH, que são em maior número no IFRS-Caxias do Sul. Nesse sentido, talvez a não oferta de recursos específicos para alunos com TDAH devase ao fato de não existir TAs específicas para essa NEE, o que demanda uma compreensão pontual desta NE para que se possa atribuir o uso de uma tecnologia acessível, caso seja necessário. Contudo, durante a observação in loco foi possível perceber que há uma preocupação por parte do NAPNE, dos docentes e da gestão de construir uma ação coordenada 
com o objetivo de qualificar o acompanhamento e a instrumentalização do atendimento dos alunos com TDAH.

A partir dessa pesquisa foi possível perceber que ainda é necessária a consolidação de um trabalho de articulação entre setores pedagógicos e NAPNE em um movimento que procure identificar a partir do público-alvo ferramentas que abarquem a maior parcela de NEEs, visto que $72 \%$ dos recursos de software não foram utilizados por alunos e professores, no ano de 2019. Ainda cabe apontar a necessidade de aquisição ou substituição das TAs do tipo software, pois conforme verificado existe um baixo movimento de adesão por parte dos professores em relação à utilização das TAs em questão, muito embora as TAs ofertadas contemplem alunos com: Paralisia Cerebral, deficiência física membros superiores e baixa visão. Dessa forma, depreende-se que se faz necessário que outras TAs sejam adquiridas, a fim de contemplar alunos com NEEs como: surdez, deficiência intelectual, etc.

Por fim, apurou-se que a Instituição possui uma gama significativa de TAs, em especial destinadas às acessibilidades para recursos computacionais do tipo software, mas que precisam estar adequadamente distribuídas em relação aos tipos de NEEs dos alunos da Instituição. Nesta perspectiva, o acompanhamento do uso das TAs e a oferta coerente das mesmas, pode promover o fortalecimento dos processos de ensino e aprendizagem dos alunos com NEE, contribuindo para a constituição de um instrumento potente de ressignificação e transformação das práticas pedagógicas dos professores. Com o intuito de dar continuidade a esse acompanhamento serão realizados estudos futuros, nos quais se pretende aprofundar a caracterização e a utilização dos recursos de Auxílio e os tipos de NEEs dos alunos que fazem uso dessas no IFRS-Campus Caxias do Sul.

\section{REFERÊNCIAS}

BERSCH, R. Introdução a tecnologia assistiva. Porto Alegre, 2017. Disponível em: https://rb.gy/1bwt1h. Acesso em: 15 fev. 2020.

BEYER, H. O. Da Integração Escolar a Educação Inclusiva: implicações pedagógicas. In: BAPTISTA, C. R. Inclusão e Escolarização: múltiplas perspectivas. 2. ed. Porto Alegre: Mediação, 2015. cap. 5. p. 73-81.

BISOL, C. A.; PEGORINI, N. N.; VALENTINI, C. B. Pensar a deficiência a partir dos modelos médico, social e pós-social. Cadernos de Pesquisa, São Luís, v. 24, n. 1, p. 87-100, jan. 2017. Disponível em: https://rb.gy/ythu45. Acesso em: 4 mar. 2020.

BRASIL. Palácio do Planalto. Decreto n. 5.296, de 2 de dezembro de 2004. Regulamenta as Leis $\mathrm{n}^{\circ} 10.048$, de 8 de novembro de 2000 , que dá prioridade de atendimento às pessoas que 
especifica, e no 10.098, de 19 de dezembro de 2000. Brasília, 3 dez. 2004. Disponível em: https://rb.gy/x8pwvk. Acesso em: 6 jul. 2019.

BRASIL. Decreto n. 6.571, de 17 de setembro de 2008. Dispõe sobre o Atendimento Educacional Especializado, regulamenta o parágrafo único do Art. 60 da Lei no 9.394, de 20 de dezembro de 1996, e acrescenta dispositivo ao Decreto no 6.253, de 13 de novembro de 2007. Brasília, DF, 18 set. 2008a. Disponível em: https://rb.gy/yy0zjf. Acesso em: 19 mar. 2020.

BRASIL. Ministério da Educação. Política Nacional de Educação Especial na Perspectiva da Educação Inclusiva. Brasília, MEC; SEEP, 2008b. Disponível em: http://portal.mec.gov.br/seesp/arquivos/pdf/politica.pdf. Acesso em: 15 maio 2020.

BRASIL. Decreto n. 7.611, de 17 de novembro de 2011. Dispõe sobre s Educação Especial, o Atendimento Educacional Especializado e dá outras Providências. Brasília, DF, 18 dez. 2011. Disponível em: https://rb.gy/3qnldq. Acesso em: 19 mar. 2020.

BRASIL. Instituto Nacional de Estudos e Pesquisas Educacionais Anísio Teixeira. Plano Nacional de Educação (PNE) 2014-2024: Linha de Base. Brasília, DF: INEP, $2015 a$. Disponível em: https://rb.gy/ob1qn8. Acesso em: 3 dez. 2019.

BRASIL. Lei n. 13.146, de 06 de julho de 2015. Lei Brasileira de Inclusão da Pessoa Com Deficiência (estatuto da Pessoa Com Deficiência). Brasília, DF, 7 jul. 2015b. Disponível em: https://rb.gy/vglkkj. Acesso em: 4 mar. 2020.

BRASIL. Lei n. 13.409, de 28 de dezembro de 2016. Reserva de Vagas Para Pessoas Com Deficiência nos Cursos Técnico de Nível Médio e Superior das Instituições Federais de Ensino. Brasília, DF, 29 dez. 2016. Disponível em: https://rb.gy/ekpok6. Acesso em: 2 jul. 2019.

CARVALHO, R. E. Educação inclusiva: com os pingos nos "is". 11. ed. Porto Alegre: Mediação, 2016. 174 p.

CAT. Subsecretaria Nacional de Promoção dos Direitos da Pessoa com Deficiência. Comitê de Ajudas Técnicas. Tecnologia Assistiva. Brasília: CORDE, 2009.

CELLARD, A. A análise documental. In: POUPART, J. et al. A pesquisa qualitativa: enfoques epistemológicos e metodológicos. enfoques epistemológicos e metodológicos. Petrópolis: Vozes, 2008. p. 295-316.

DINIZ, D.; BARBOSA, L.; SANTOS, W. R. Deficiência, direitos humanos e justiça. Sur. Revista Internacional de Direitos Humanos, São Paulo, v. 6, n. 11, p. 64-77, dez. 2009. Disponível em: https://rb.gy/cmshoz. Acesso em: 5 maio 2020.

GARCIA, M. F. et al. Novas competências docentes frente às tecnologias digitais interativas. Teoria e Prática da Educação, Maringá, v. 14, n. 1, p. 79-87, fev. 2012. Disponível em: https://rb.gy/hblmko. Acesso em: 21 abr. 2020.

MAIA, C. C. V. As diferenças entre softwares livres e gratuitos. Anais do Congresso Nacional Universidade, Ead e Software Livre, Belo Horizonte, v. 2, n. 2, p. 1-3, jun. 2011. Disponível em: https://rb.gy/ywxr1n. Acesso em: 21 abr. 2020.

ORLANDO FILHO R. et al. O uso do software comunique como recurso tecnológico no processo de ensino e aprendizagem de aluno(s) com paralisia cerebral. Renote: Novas

RPGE- Revista on line de Política e Gestão Educacional, Araraquara, v. 24, n. 3, p. 1242-1256, set./dez. 2020. e-ISSN:1519-9029. 
Tecnologias na Educação, Porto Alegre, v. 4, n. 2, p. 1-9, dez. 2006. Disponível em: https://rb.gy/cszyrn. Acesso em: 15 abr. 2020.

SAMPIERI, R. H.; COLLADO, C. F.; LUCIO, M. P. B. Metodologia de pesquisa. 5. ed. Porto Alegre: Penso, 2013. 624 p.

SONZA, A. P. et al. (org.). Acessibilidade e tecnologia assistiva: pensando a inclusão sociodigital de PNEs. Bento Gonçalves: Instituto Federal do Rio Grande do Sul, 2013.

SONZA, A. P.; SALTON, B. P.; STRAPAZZON, J. A. (org.). O uso pedagógico dos recursos de tecnologia assistiva. Porto Alegre: Companhia Rio-grandense de Artes Gráficas, 2015. cap. 4. p. 108-164.

VIGOTSKI, L. S. A formação social da mente. 4. ed. São Paulo: Martins Fontes, 1991. 168 p.

\section{Como referenciar este artigo}

MORO, T. B.; CORRÊA, Y.; VALENTINI, C. B.; MARCOLlA, V.; CARDOSO, E. Tecnologias assistivas e necessidades educacionais específicas: da oferta de recursos de software ao público-alvo. Revista on line de Política e Gestão Educacional, Araraquara, v. 24, n. 3, p. 1242-1256, set./dez. 2020. e-ISSN:1519-9029. DOI: https://doi.org/10.22633/rpge.v24i3.13967

Submetido em: 21/07/2020

Aprovado em: $30 / 08 / 2020$

Publicado em: 01/09/2020 